\title{
Passenger sharing of the high-speed railway from sensitivity analysis caused by price and run-time based on the multi-agent system
}

\author{
Ma Ning ${ }^{1 *}$, Yin $\mathrm{Ge}^{2}$, Zuo Yang ${ }^{1}$ \\ ${ }^{1}$ Beijing Forestry University, (China) \\ ${ }^{2}$ The Chinese University of Hong Kong (China) \\ "blyz0727@gmail.com
}

\section{A bstrad:}

Purpose Nowadays, governments around the world are active in constructing the high-speed railway. Therefore, it is significant to make research on this increasingly prevalent transport.

Design/methoddogy/approadr. In this paper, we simulate the process of the passenger's travel mode choice by adjusting the ticket fare and the run-time based on the multi-agent system (MAS).

Findings: From the research we get the conclusion that increasing the run-time appropriately and reducing the ticket fare in some extent are effective ways to enhance the passenger sharing of the high-speed railway.

Originality/value We hope it can provide policy recommendations for the railway sectors in developing the long-term plan on high-speed railway in the future.

Keywords: high-speed railway, passenger sharing, multi-agent system, price, run-time 


\section{Introduction}

In recent years, the high-speed railway has been the main trend of the world railway development rapidly because of its energy-saving, light pollution, safety, comfort, combined with its unique advantages in terms of the technology and the socio-economic. Currently, there are 12 countries in the world have built the high-speed railway with speed over 200 kilometers per hour. Besides, Switzerland, Austria and other seven countries are also under active construction. Chinese high-speed railway network consists of the backbone network, the important area network, and the intercity high-speed railway between major cities. According to the plan, Chinese high-speed railway will reach more than 16,000 kilometers by 2020 . By that time, the "four vertical and four horizontal passenger dedicated line", as well as the intercity passenger transportation system in economically developed cities and densely populated regions will be accomplished. Together with the speed up of the other new railway and existing lines to be speeded, Chinese rail network will be up to 50,000 kilometers or more, which connecting all capital cities with big cities where the population is over 500,000, and covering ninety percent of mainland population.

The prosperity and the development of high-speed railway will have a profound impact on China's overall passenger and freight transport modes. First of all, within the distance range of 200-1000 km, high-speed railway has shorter run-time compared with the aviation and the highway. Meanwhile, it has more comfortable travel space. Secondly, the development of the high-speed railway is significant to freight in rail and aviation.

Among all the factors which can affect the passengers' decision of travel mode, ticket fare and run-time are the two most major factors. In this paper, we use the multi-agent system (MAS) to simulate the process when the passengers choose the travel modes. By this method, we can get the conclusion that lower ticket fare and reasonable deceleration should be considered by the Ministry of Railways to improve the passenger sharing of the high-speed railway.

\section{Research status}

Traffic share prediction research first originated in the study of the urban transportation planning in the transportation mode split. How to optimize the passenger sharing is an essential issue researched by many scholars. The foreign researches on the passenger share started in the early 1950s. The early scholars mainly solved the transportation division problems from the perspective of aggregation. The PugetSound classification prediction model (Sheffi, 1985) was one of the first models to predict the passenger share. However, this model involves a very wide range of survey and classification, so it does not apply to large cities in the traffic forecast. In the 1960s, many scholars have proposed the shift curse method (Bolduc, 1999) which has been widely used in the 60s and 70s in the 20th century. In the 1970s, economist McFadden (1973) cited the utility theory and proposed the Logit model 
based on the random utility model. The model which is widely used later is based on the probability theory from the perspective of disaggregated method. From then on, the disaggregated model is widely utilized to study transportation mode split. Ganek and Saulino (1976) have predicted the mode choices of the commuters by split model in 1976. Koppleman (1976) has used the cluster analysis to aggregate disaggregated choice models and obtained an aggregated model structure. In 2003, Lee, Lee and Park (2003) have estimated the price and service elasticity of passenger using stated preference and sample enumeration methodology, and they also analyzed the effects of hypothetical travel demand management policies by changes on modal share using the elasticity estimates. Gao, Luo, Gao and Li (2010) build a passenger transport model and add Metrics in Logit model based on the selection of all travel methods to estimate the passenger sharing of expressway and other transport models. Ma, Zhang and Zhao (2003) use the Logit model to estimate the passenger share between the high-speed railway and the aviation. Xie, Qiu, Li and Wang (2006) use the improved Logit model to calculate the passenger share of different transport models in the GuangZhouShenZhen transport market.

However, the estimation and data issues from these modes are often far from clear. Indeed there is a great deal of potential inaccurate inference obtained from data that are often not able to comply with demands of mixed Logit models. Moreover, every passenger in disaggregate model is treated as independent research object. Their inner-relation is ignored. It is unreasonable in the case of the study on travel mode because the factors that affect the passenger's travel choice are interrelated. Only when we analyze and clarify the interaction of these factors can we grasp the relationship of different transport models and the passenger's travel choice mechanism. The Agent based modeling method provides us a new way to solve this problem.

The Agent based modeling, with direct historical roots in complex adaptive systems (CAS), is a stochastic simulation modeling approach that provides the unique capability to explore the non-linear, adaptive interactions with their own dynamic behavior and heterogeneous characteristics (Heckbert, Baynes \& Reeson, 2010). The Agents interact with each other and their environment, resulting in emergent outcomes at the macro-scale that can be used to quantitatively analyze complex systems. The Agent based modeling has been used in a wide variety of domains such as planning military operations (Hoogendoorn, Jonker, van Maanen \& Treur, 2009), understanding Web services management (Ding, Sun \& Hao, 2007), monitoring workflow (Wang, Wang \& Xu, 2005) and traffic simulation (Fujii, Yoshimura \& Seki, 2010), etc.

As for the aspect of traffic simulation, Fiosins, Fiosina and Mueller (2011) present an approach for integrated decision making of vehicle agents in urban traffic systems. Zheng, Waraich, Axhausen and Geroliminis (2012) have combined a macroscopic model of traffic congestion in urban networks with an agent-based simulator to study congestion pricing schemes. Bhouri, 
Balbo and Pinson (2012) propose a bimodal urban traffic control strategy based on a multiagent model to improve global traffic, reduce bus delays and improve bus regularity in congested areas of the network. Handford and Rogers (2011) present an agent-based behavior model based on the social forces model of crowds and use utility-based path trees to represent the forces which affect a driver's decisions. Xu and Luo (2012) build a multi-agent based model to simulating urban intelligent transport system. Meng, Lu, Lai and Xu (2012) describe a reliability prediction approach to the train's control and monitoring system based on the multiagent model and simulation.

The development of the high-speed railway has drawn the contribution of a great number of scholars, but the research on the magnitude of the increase of the passenger sharing is limited. Therefore, we use the Agent based modeling to establish a multi-agent system that are built from the ground-up to simulate the passenger agents' travel choice behavior and research the passenger sharing problems.

\section{Passenger share simulation model}

\subsection{Model introduction}

The multi-agent-based simulation model is a class of computational models for simulating the actions and interactions of autonomous agents (both individual and collective entities such as organizations or groups) with a view to assess their effects on the system as a whole. In this paper, the model we used to describe the passenger sharing is constituted by a host of passenger agents. These agents have to make a final decision within a variety of travel modes according to their preferences such as ticket fare, run-time and so on, and different agents choose different travel mode. Thus, we can calculate the sharing ratio of each travel modes according to respective passenger sharing. In fact, all of the agents in our model will choose the travel mode in each simulation cycle. Therefore, the sum sharing ratio of all modes is 1 .

\subsection{Passenger agent model}

\subsubsection{Agent's behavior selection mechanism}

The core of the simulation model is to build the passenger agents' behavior selection mechanism. In fact, passengers have various requirements while traveling, and their choices of travel mode differ from each other. For instance, as for the low-income people who intend to visit relatives, the ticket fare is the main factor that affects their decision-making. They prefer ordinary railway or road which is relatively cheaper. When it mentioned to the business travelers whose income is higher, they tend to take the run-time and comfort into consideration. So the high-speed railway and civil aviation become their primary selection. 
In our simulation, agent's behavior selection mechanism is depicted by an act decision-making chain. Different act decision-making chains describe agent's different characteristics when choosing the travel mode. We designed the chain carefully and elaborately. Eventually, we chose the best one to represent the choice characteristics of each agent, which is in total 26 binary codes and consists of one initial section and four decision-making sections. The initial section decided agent's first choice and the decision-making section declare the following decision.

Each decision-making section consists of 6 binary codes. Agent's select state is illustrated by the first and second code. Specifically, 00 means high-speed railway, 01 means common train, 10 means civil aviation and 11 means road. When agents are pleased with their current choice, the third and the fourth code on behalf of their following transform state, 00 to section one, 01 to section two, 10 to section three and 11 to section four. The last two codes stand for the following transform state if agents are displeased.

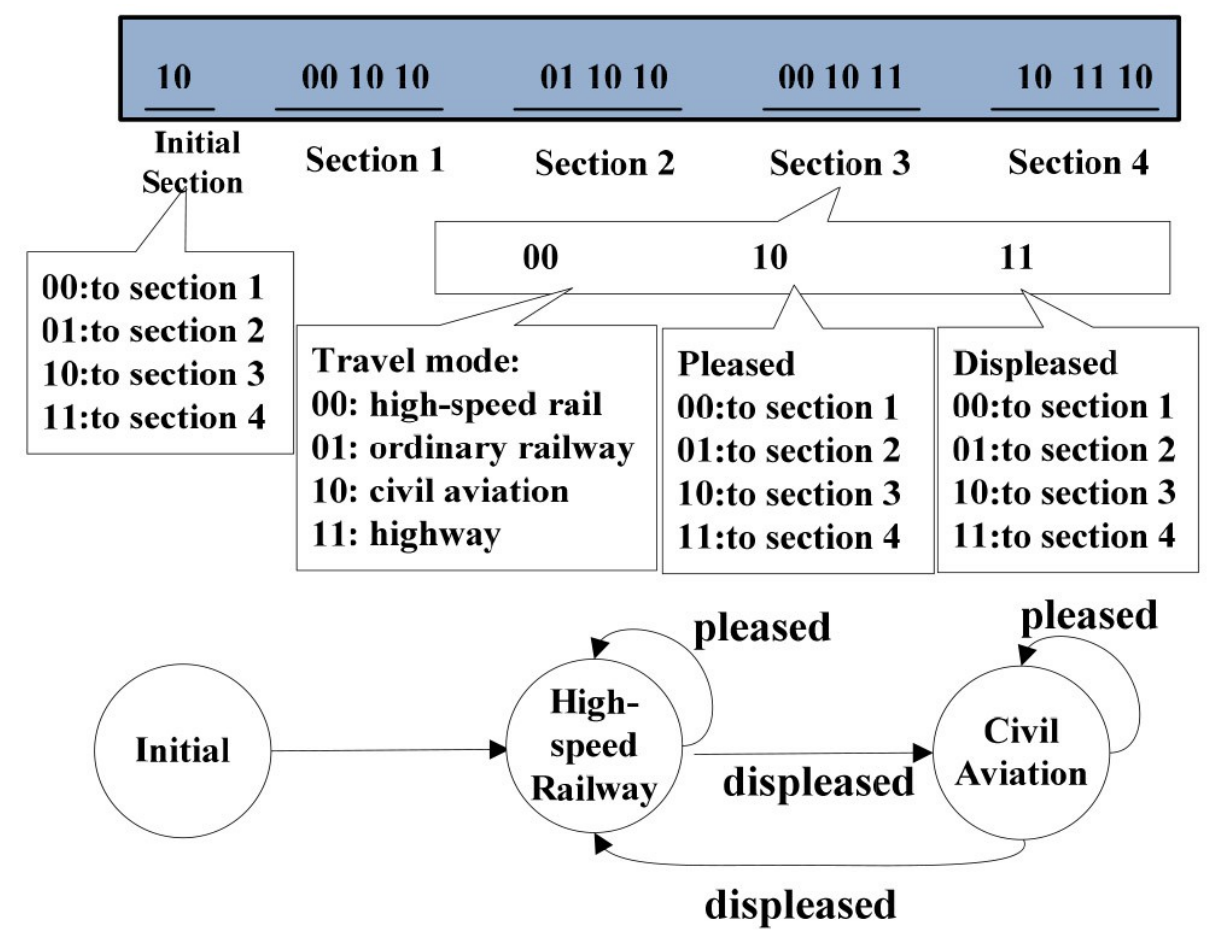

Figure 1. Act Decision-making Chain of Business Passenger

As shown in Figure 1, according to the rule of the chain, this agent would choose high-speed railway firstly, and continue to choose it if he is pleased, otherwise he would turn to civil aviation. When he chooses civil aviation, he will go on with it until he is displeased and take high-speed railway as an alternative. Therefore, this agent belongs to a business traveler type. Similarly, as shown in Figure 2, high way is the agent's preferred choice in accordance with the rule of the chain. He would choose ordinary railway once he is displeased with the high way. The ticket fare of the aviation and high-speed railway is higher to this type agent. Thus, it can be classified as low-income passenger type. 


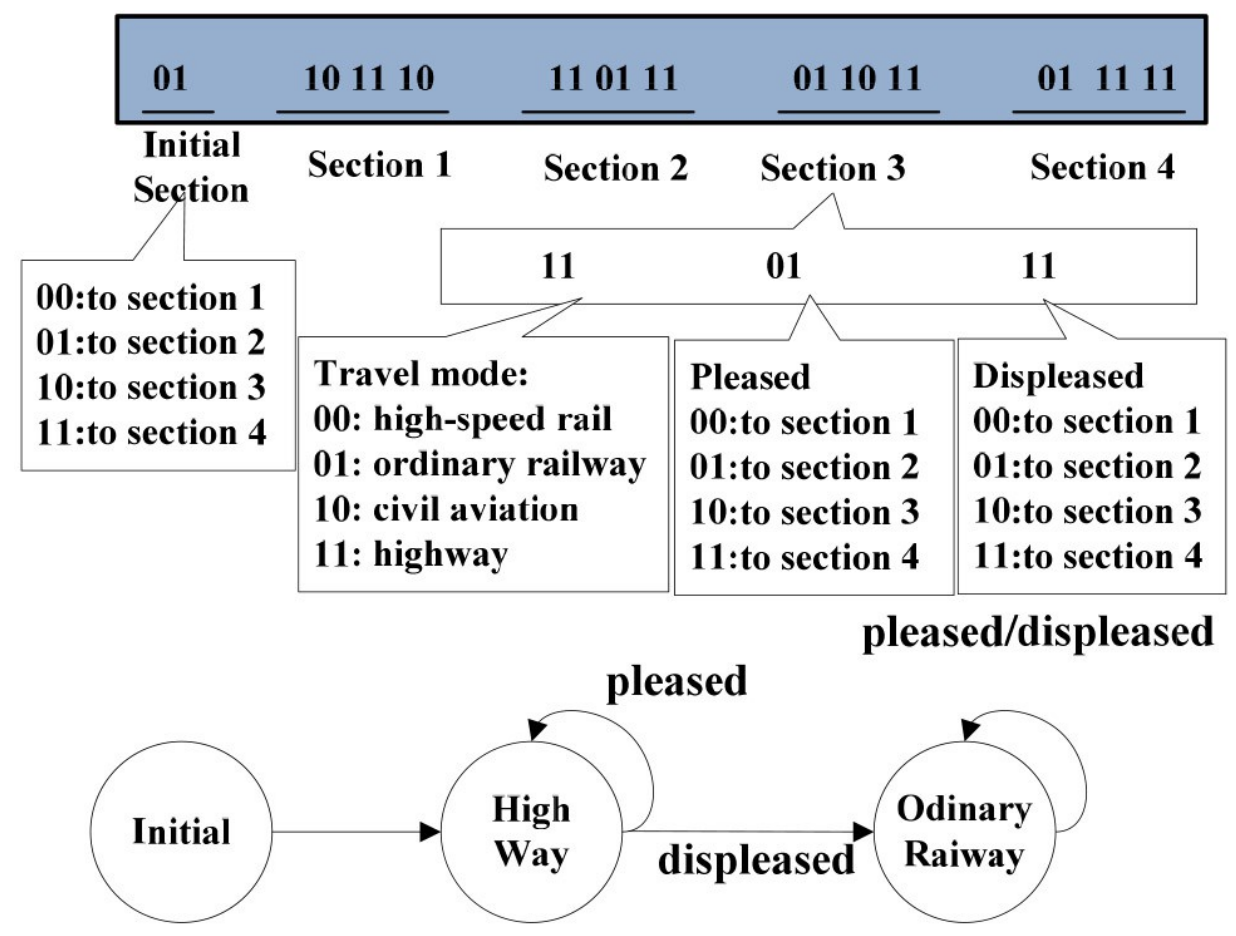

Figure 2. Act Decision-making Chain of Low-income Person

\subsubsection{Agent's learning mechanism}

The agent in our simulation has strong autonomy and learning skills. At present, the models that can be applied to self-learning are genetic algorithm (Zhu, Xu \& Zhu, 2010) and neural network method (Xiao \& Zhang, 2009). We use the first one to depict the learning characteristics of our agents, which includes three categories: the elimination, the crossover and the mutation. To this end, we set three mechanisms below for the agents.

\subsubsection{Agent's elimination mechanism}

The act decision-making chain of each agent is randomly generated during the initialization, so they will choose the travel mode on full basis of the chain. In this way, there must be some of agents that are not such intelligent and always been in "displeased state". Therefore, we need to phase out these agents by setting a threshold value, once an agent's displeased rate exceeds this value, he will be eliminated.

\subsubsection{Agent's crossover mechanism}

The eliminated one will be replaced by a new agent who has learned the most successful agent's decision-making rule within his effective range before entering into the model. In the learning process, the original agent' chain intersect with the best passenger agent' chain within his effective radius upon the random cross-ratio and create a new chain. Because of the information from the excellent agent's chain, the original agent's intelligent has been improved. For example, after the crossover mechanism mentioned, the chain in Figure 1 and the chain in Figure 3 produce a new chain shown in Figure 3. 


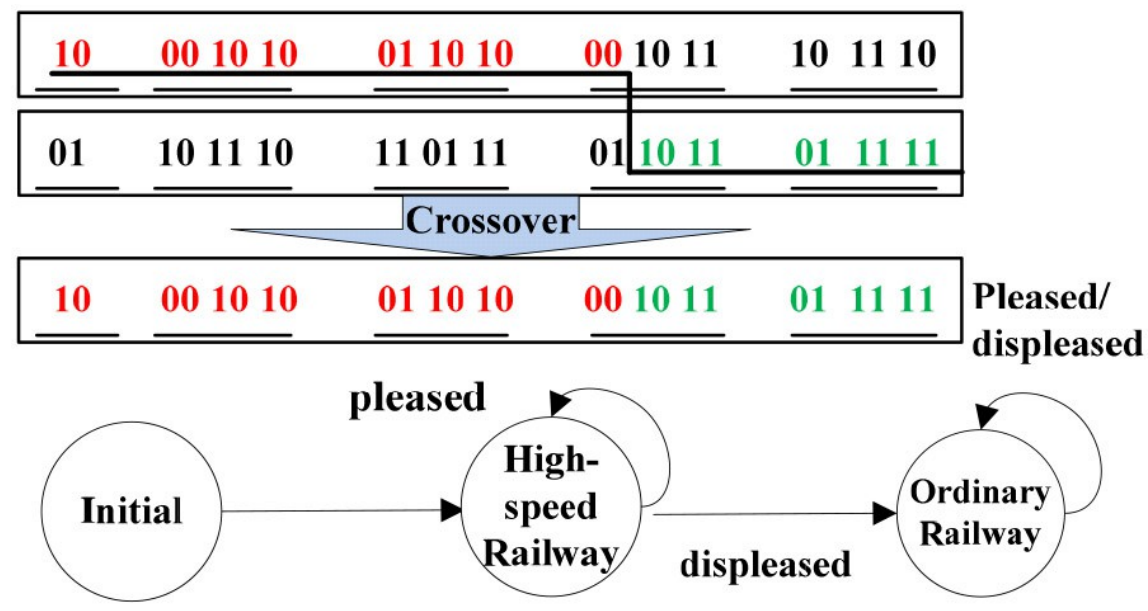

Figure 3. The Crossover Mechanism of Passenger Agent

It can be seen in Figure 3 that the generated agent belongs to railway preference, the highspeed railway is his first choice and the ordinary railway the second. Once he turns to the ordinary railway, he would always choose it no matter how he feels.

\subsubsection{Agent's mutation mechanism}

The new chain could mutate and generate another one. The code " 1 " and " 0 " may convert to each other, and the mutate position, as well as the quantity are random. The agent in Figure 3 will change into a different one in Figure 4 through mutation mechanism. The generated passenger agent is an ordinary railway traveler who will not consider other travel modes.

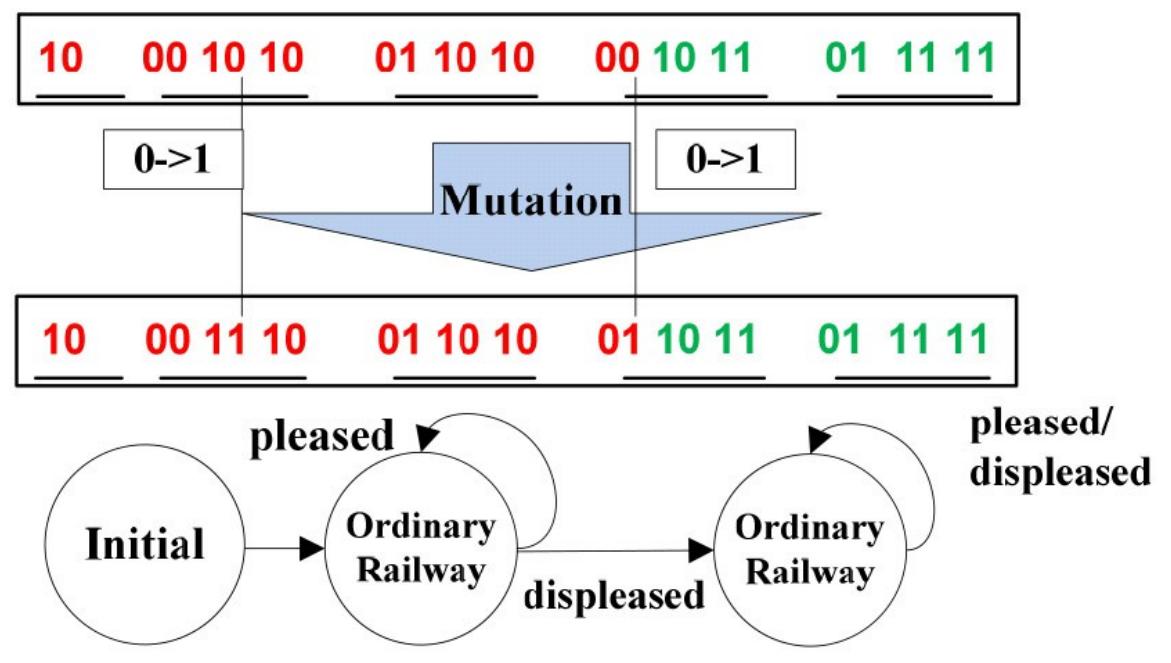

Figure 4. The Mutation Mechanism of Passenger Agent

\subsection{The simulation process}

The simulation process is listed below:

Step 1. Set environmental parameters. These parameters consist of the number of the passenger agents, the simulation cycle, and the transport capacity parameter of different travel modes as well. 
Step 2. Initialize the Agent. To generate random act decision-making chain for each agent, by which agents can make their choice.

Step 3. Optimize the Agent. To calculate the cumulative satisfaction rate for each agent, then compare this rate with the pre-set threshold. The agent would be replaced by new agent if the rate less than the threshold. A new agent will generate by crossover mechanism and mutation mechanism

Step 4. Simulate the traffic sharing and cycle. According to the decision-making satisfaction, agents select next section and enter into the following cycle.

Step 5. Finish the Simulation. Analyze the results and make policy recommendations for the transport sectors. The whole simulation process is shown in Figure 5.

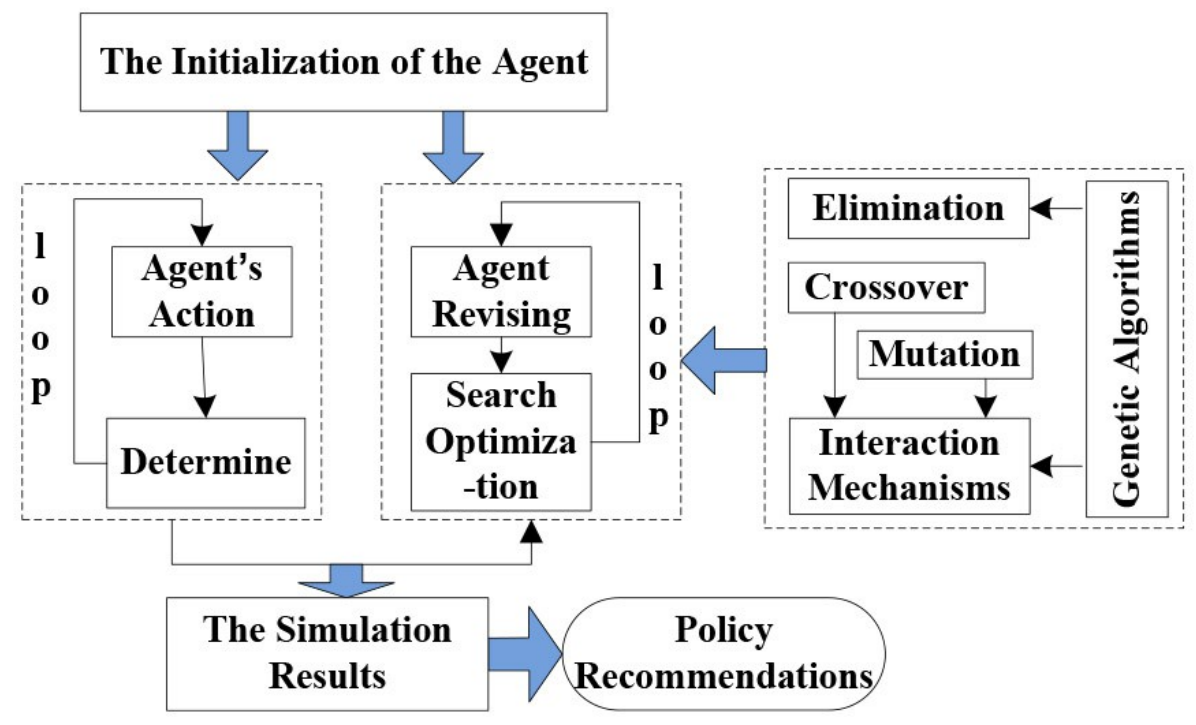

Figure 5. The Simulation Process

\section{Simulation results}

Given the impossibility of the adjustment in reality, we set up the adjustment scope from $50 \%$ to $130 \%$ both in ticket fare and run-time. For each adjustment, we simulate repeatedly for 10 times and calculate the standard deviation so that we can get accurate and stable result.

After the simulation, we obtained the conclusion as follows:

Firstly, in the respective of the ticket fare adjustment, it is shown in Table 1 clearly that the cheaper the ticket fare is, the more passengers prefer the high-speed railway. Furthermore, we can see in Figure 6 that the sharing rate increases fastest when the ticket fare is reduced to $70 \%$.

Secondly, as shown in Figure 6, we can see that the change of sharing rate is not obvious when the ticket fare is increased. To start with, a host of passengers who choose high-speed 
railway are rigid demanders. In the survey we conducted in 2010 ( $\mathrm{Ma}, \mathrm{Xu}, \mathrm{Xie} \& \mathrm{Li}, 2011$ ), we designed 28 questions involved indexes about ticket fare and speed to study what factors influence passenger most. Among passengers who take high-speed railway, the proportion of higher income earners (people whose monthly income are greater than 5000) is 56.25\% and $28.8 \%$ of them are on business at public expense. Therefore, improving the high-speed price won't affect their travel obviously because of their low ticket fare sensitivity. In contrast, reducing the ticket fare has significant impact on the sharing rate of high-speed railway. The reason is that $20 \%$ of passengers in our survey considered that the current ticket fare is higher to them. Consequently, there will be more passengers take high-speed railway if the ticket fare can be lower.

\begin{tabular}{|c|c|c|c|c|c|}
\hline \multirow{2}{*}{$\begin{array}{l}\text { Ticket Fare } \\
\text { Adjustment }\end{array}$} & \multicolumn{2}{|c|}{ Sharing Rate of High-speed Rail } & \multirow{2}{*}{ Run-time Adjustment } & \multicolumn{2}{|c|}{ Sharing Rate of High-speed Rail } \\
\hline & Sharing Rate & Standard Deviation & & Sharing Rate & Standard Deviation \\
\hline Reduced to $50 \%$ & $34.32 \%$ & $1.40 \%$ & Reduced to $50 \%$ & $33.52 \%$ & $0.69 \%$ \\
\hline Reduced to $60 \%$ & $32.00 \%$ & $0.96 \%$ & Reduced to $60 \%$ & $29.15 \%$ & $0.63 \%$ \\
\hline Reduced to $70 \%$ & $29.41 \%$ & $1.06 \%$ & Reduced to $70 \%$ & $25.66 \%$ & $0.98 \%$ \\
\hline Reduced to $80 \%$ & $23.70 \%$ & $0.84 \%$ & Reduced to $80 \%$ & $23.16 \%$ & $0.52 \%$ \\
\hline Reduced to $90 \%$ & $22.13 \%$ & $1.48 \%$ & Reduced to $90 \%$ & $21.88 \%$ & $0.85 \%$ \\
\hline Unadjusted & $20.95 \%$ & $0.86 \%$ & Unadjusted & $20.95 \%$ & $0.86 \%$ \\
\hline Increased to $110 \%$ & $20.00 \%$ & $1.26 \%$ & Increased to $110 \%$ & $20.11 \%$ & $0.94 \%$ \\
\hline Increased to $120 \%$ & $19.16 \%$ & $0.51 \%$ & Increased to $120 \%$ & $18.24 \%$ & $0.83 \%$ \\
\hline Increased to $130 \%$ & $18.37 \%$ & $0.86 \%$ & Increased to $130 \%$ & $16.98 \%$ & $0.79 \%$ \\
\hline
\end{tabular}

Table 1. The Influence of the Ticket Fare and Run-time Adjustment on the Passenger-sharing Ratio

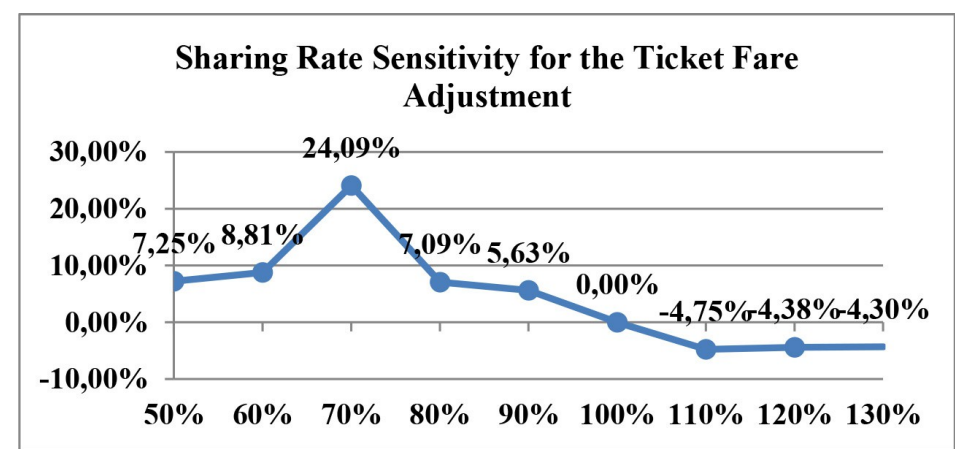

Figure 6. Sharing Rate Sensitivity Line Chart After Ticket Fare Adjustment

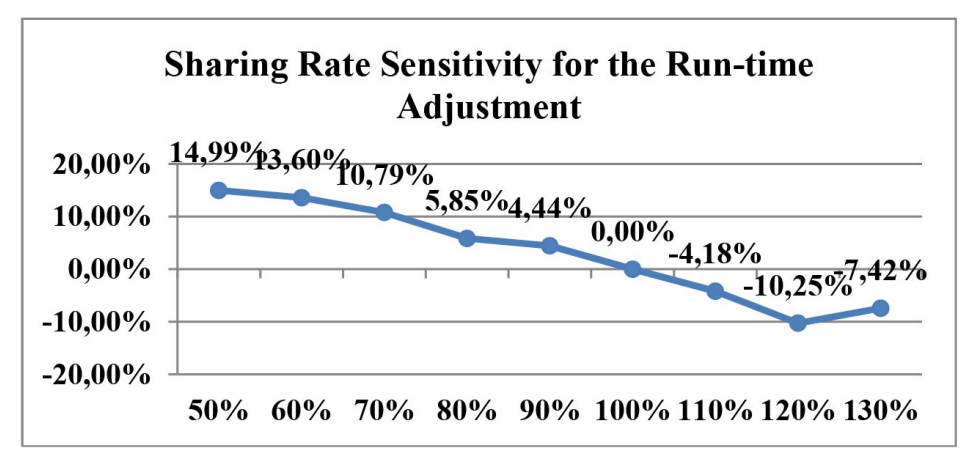

Figure 7. Sharing Rate Sensitivity Line Chart After Run-time Adjustment 
We all know that the relative quick speed is the main superiority of the high-speed railway, but different from the opinion we hold before that long run-time would reduce the passenger sharing. the simulation result in Table 1 and Figure 7 shows that enhancing the run-time legitimately would not cause obvious influence on the sharing rate. Simultaneously, reducing the speed is the main contributor to the safety of the high-speed railway. In summary, from the point of view of both speed and ticket fares, increasing the run-time appropriately and decreasing the ticket fare in some extend is an effective way to enhance the sharing rate of high-speed railway.

\section{Conclusion}

With the faster speed, shorter run-time, more comfortable condition and lower ticket fare, the high-speed railway has shown its strength and will have continuous development undoubtedly all over the world.

Before the rapid development of China's high-speed railway, high-speed railway has been developed in Japan, France, Germany, Italy and other countries. Among these, France TGV, Japan's Shinkansen, Eurostar and German ICE are the comprehensive ones. The Shanghai-Hangzhou line's operation mileages is 202 km, and take it as a comparison standard, these well-known high-speed railways' ticket fares and the proportion accounting for GNP per capita are shown in Table 2.

Obviously, the existing ticket fare in China is slightly higher than the passengers' acceptance in contrasting with France and Japan, thus, it can be considered to implement a discount on the basis of the original ticket fare to improve the sharing ratio of high-speed railway.

Similarly, we compared the speed of Shanghai-Hangzhou line with other countries' high-speed railway system, and it is obviously that except the speed of France TGV go up to $320 \mathrm{~km} \mathrm{/} \mathrm{h,}$ the rest of the high-speed railway system running slower than the speed of $300 \mathrm{~km} / \mathrm{h}$. In fact, all of these high-speed railway systems operate slower than the speed they have designed. Running safely and stably for nearly 40 years, these high-speed railways can also suggest that the lower speed would not affect the passenger-sharing ratio.

\begin{tabular}{|l|c|c|c|}
\hline & Ticket Fares & GNP Per Capita & Proportion \\
\hline France TGV & 354 & 272173 & $0.13 \%$ \\
\hline Japan's Shinkansen & 459 & 264761 & $0.17 \%$ \\
\hline Eurostar & 890 & 242336 & $0.37 \%$ \\
\hline Shanqhai-Hanqzhou & 82 & 26758 & $0.31 \%$ \\
\hline
\end{tabular}

Table 2. Ticket Fares and the Proportion Accounting for GNP Per Capita

The China's ministry of railways has made some adjustments to the high-speed railway from Shanghai to Nanjing. In the first place, the speed decreased from 350 to $300(\mathrm{~km} / \mathrm{h})$ from August 11, 2011, as the result, the run-time increased from 45 to 50 ( $\mathrm{min}$ ). Secondly, in this 
year from May 18 to June 20 11, six lines from Shanghai to Nanning and Shanghai to Nanjing adjusted their ticket fare. The ticket fare declined by $30 \%$ (business class seat) and $10 \%$ (principal seat) respectively. After this special deal, the business class seat from Shanghai to Nanning fell from 438 to 307 and the ticket fare of principal seat now is 237 compared to 263 before. In addition, Shanghai Railway Bureau has decided to make timely adjustment to the special deals period, the train range and the margin of preference according to different transport seasons and the demand of passengers intending to attract more passenger.

Apart from the Shanghai-Nanjing line, the Ministry of Railways also conducts other reasonable adjustments to the remaining lines. For instance, from 11 August 2011, the speed of BeijingTianjin intercity high-speed railway dropped from 350 to $300(\mathrm{~km} / \mathrm{h})$, at the same time, the speed of high-speed railway from Hefei to Nanjing, Hefei to Wuhan, Shijiazhuang to Taiyuan, Nanchang to Jiujiang, Ningbo to Xiamen, Changchun to Jilin, Qinhuangdao to Shenyang and the East loop line in Hainan declined by $50 \mathrm{~km}$ per hour. With the dropping of the speed, the run-time is prolonged, and the ticket fare of different levels downward by 5 percent on the basis of the current ticket fare. Moreover, the number of high-speed railway trains from Beijing to Shanghai reduced by 22 .

The adjustments mentioned all above are the practical proof of our theoretical analysis. In the aspect of the run-time, after the speed regulation in 2011, the number of short-distance passengers in the East China is still showing a tremendous rise. During the Spring Festival in 2012, there is a surge in traffic exceeding the previous Spring Festival significantly. In addition, as for the ticket fare we obtained information from the website of the Railway Customer Service Center, although the special ticket fare is cheaper, people still rarely purchased. This situation occurred both in the interval from Shanghai to Nanjing and to Hangzhou. The fact demonstrates that the high-income people who take high-speed railway are not sensitive to the ticket fare. Thus, if we want more people to choose the high-speed railway, what we should do is to lower the ticket fare of first-class and second-class. Only in this way, would people consider that the ticket fare of the high-speed railway is more affordable.

\section{Acknowledgments}

The paper is supported by the Beijing Higher Education Young Elite Teacher Project (No.BJQNYC201341) and the Humanities and Social Sciences Planning Fund Supported by Chinese Ministry of Education (No.12YJAZH090).

\section{References}

Bhouri, N., Balbo, F., \& Pinson, S. (2012). An agent-based computational approach for urban traffic regulation. Progress in Artificial Intelligence, 1(2), 139-147. http://dx.doi.org/10.1007/s13748-012-0011-0 
Bolduc, D. (1999). A practical technique to estimate multinomial probit models in transportation. Transportation Research Part B: Mehtodological, 33(1), 63-79. http://dx.doi.org/10.1016/S0191-2615(98)00028-9

Ding, Y., Sun, H., \& Hao, K. (2007). A bio-inspired emergent system for intelligent web service composition and management. Knowledge-Based Systems, 20(5), 457-465. http://dx.doi.org/10.1016/j.knosys.2007.01.007

Fiosins, M. , Fiosina, J., \& Mueller, J.P. (2011). Agent-based integrated decision making for autonomous vehicles in urban traffic. Advances on Practical Applications of Agents and Multiagent Systems, 88, 173-178.

Fujii, H., Yoshimura, S., \& Seki, K. (2010). Multi-agent based traffic simulation at merging section using coordinative behavior model. Computer Modeling in Engineering \& Sciences, 63(3), 265-282.

Ganek, J., \& Saulino, R. (1976). A disaggregate modal-split model for work trips involving three mode choices. Transportation Research Record, (610), 25-29.

Gao, H.I., Luo, Y., Gao, L.Y., \& Li, H. (2010). Passenger-sharing rate model of new expressway under integrated passenger transport channel. International Conference on Intelligent Computation Technology and Automation, 2, 880-883.

Handford, D., \& Rogers, A. (2011). Modelling driver interdependent behaviour in agent-based traffic simulations for disaster management. Advances on Practical Applications of Agents and Multiagent Systems, 88, 163-172.

Heckbert, S., Baynes, T., \& Reeson, A. (2010). Agent-based modeling in ecological economics. Annals of the New York Academy of Sciences, 1185, 39-53. http://dx.doi.org/10.1111/j.17496632.2009.05286.x

Hoogendoorn, M., Jonker, C.M., van Maanen, P.P., \& Treur, J. (2009). Agent-based analysis and simulation of meta-reasoning processes in strategic naval planning. Knowledge-Based Systems, 22(8), 589-599. http://dx.doi.org/10.1016/j.knosys.2009.05.003

Koppleman, F.S. (1976). Guidelines for aggregate travel prediction using disaggregate choice models. Transportation Research Record, (610), 19-24.

Lee, S., Lee, Y.H., \& Park, J.H. (2003). Estimating price and service elasticity of urban transportation demand with stated preference technique: Case in Korea. Transportation Research Record, 1839(1), 167-172. http://dx.doi.org/10.3141/1839-19 
Ma, N., Xu, L.N., Xie, F.F., \& Li, X.M. (2011). Reduction of the influential factors of railway passenger demand based on rough set. Applied Mechanics and Materials, 58, 112-117. http://dx.doi.org/10.4028/www.scientific.net/AMM.58-60.112

Ma, B.T., Zhang, Y.X., \& Zhao, C.X. (2003). Estimation of the distributing rates of high-speed passenger flows with the logit model. Journal of Northern JiaoTong University, 27(2), 66-69.

Meng, L.Z., Lu, M.Y., Lai, J., \& Xu, X.J. (2012). A multi-agent based approach to reliability prediction of train's control and monitoring software system. International Journal of Digital Content Technology and its Applications, 6(12), 149-157. http://dx.doi.org/10.4156/jdcta.vol6.issue12.18

Sheffi, Y. (1985). Urban transportation network. California: Prentice-Hall Inc.

Wang, M., Wang, H., \& Xu, D. (2005). The design of intelligent workflow monitoring with agent technology. Knowledge-Based Systems, 18(6), 257-266. http://dx.doi.org/10.1016/j.knosys.2004.04.012

Xiao, Z., \& Zhang, S.Y. (2009). Agent individualized action selection based on neural network. Computer Engineering, 35(24), 199-201.

Xie, R.H., Qiu, Z.Q., Li, Q.Y., \& Wang, R.H. (2006). Application of logit model in estimating the distribution rate of passenger flows on Guangzhou-Shenzhen railway. China Railway Science, 27(3), 111-115.

Xu, J., \& Luo, J. (2012). A study of multi-agent based model for urban intelligent transport systems. International Journal of Advancements in Computing Technology, 4(6), 126-134. http://dx.doi.org/10.4156/ijact.vol4.issue6.15

Zheng, N., Waraich, R.A., Axhausen, K.W., \& Geroliminis, N. (2012). A dynamic cordon pricing scheme combining the Macroscopic Fundamental Diagram and an agent-based traffic model. Transportation Research Part A: Policy and Practice, 46(8), 1291-1303. http://dx.doi.org/10.1016/j.tra.2012.05.006

Zhu, Y.G., Xu, Y.P., \& Zhu, Y.F. (2010). Adaptive genetic algorithm design and implementation consist of learning mechanism. Computer Engineering and Applications, 46(36), 34-39.

Journal of Industrial Engineering and Management, 2013 (www.jiem.org)

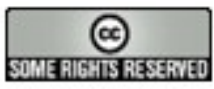

Article's contents are provided on a Attribution-Non Commercial 3.0 Creative commons license. Readers are allowed to copy, distribute and communicate article's contents, provided the author's and Journal of Industrial Engineering and Management's names are included. It must not be used for commercial purposes. To see the complete license contents, please visit http://creativecommons.org/licenses/by-nc/3.0/. 